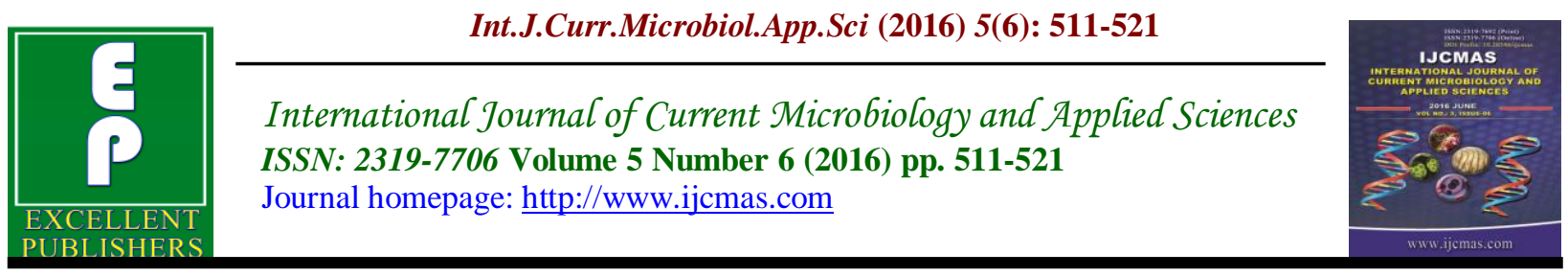

Original Research Article

http://dx.doi.org/10.20546/ijcmas.2016.506.057

\title{
Study of Bacterial Profile in Neonatal Sepsis and their Antibiotic Sensitivity Pattern in a Tertiary Care Hospital
}

\author{
K.V.Leela ${ }^{1}$, R.Narayana Babu ${ }^{2}$, Sugunya ${ }^{2}$, Venkata Madhu Prasad ${ }^{3}$ \\ and Ramisetty Raaga Deepa ${ }^{1}$ \\ ${ }^{1}$ Department of Microbiology, Govt. Kilpauk, Medical College and Hospital, Chennai, India \\ ${ }^{2}$ Department of Pediatrics, Govt. Kilpauk, Medical College and Hospital, Chennai, India \\ ${ }^{3}$ Academic officer, Govt. Kilpauk Medical College and Hospital, Chennai, India \\ *Corresponding author
}

\section{Keywords}

Neonatal sepsis, Multidrug resistance, Septicemia.

\section{Article Info}

Accepted: 20 May 2016 Available Online: 10 June 2016

\section{A B S T R A C T}

Septicemia remains a significant cause of morbidity and mortality in the newborns. The main objective of the study was to identify the common bacterial pathogens associated with neonatal sepsis and their antibiotic sensitivity pattern. During July 2015 and August 2015, 232 Blood samples were collected aseptically from newborns with sepsis in Govt. Kilpauk Medical College, Chennai and processed by standard conventional method. Antibiotic susceptibility pattern of isolates was studied by Kirby Bauer Disc diffusion technique as per the CLSI recommendations. 83 out of 232 cases were culture positive, giving a culture positivity rate of around $35.77 \%$. Males were more affected than their female counterparts. $85.5 \%$ of cases are reported in the early days of life and Gram negative bacilli were found to be the commonest cause of neonatal septicemia $(56.5 \%)$. Klebsiella pneumonia $(39.75 \%)$ was the most frequent isolate which showed $90.9 \%$ sensitivity against Amikacin. All the Gram negative bacilli were found to be highly sensitive to third generation cephalosporins especially Cefperazone sulbactum. All the gram positive isolates showed $100 \%$ sensitivity to Vancomycin. The study concludes that it is important to continue the tracking of neonatal septicemia in order to closely monitor the changes in trends, to obtain information for empiric antibiotic therapy and to act rapidly in case of emergencies. Since Govt. Kilpauk Medical College being a tertiary health care centre, most of its sepsis cases are referred ones. Hence awareness should be created about institutional deliveries along with antenatal and postnatal care.

\section{Introduction}

Neonatal sepsis is a clinical syndrome characterized by systemic signs of infection and accompanied by bacteremia in the $1^{\text {st }}$ month of life.
It is an important cause of morbidity and mortality among neonates. World Health Organization has estimated that 1.6 million deaths occur globally every year due to 
neonatal infections and $40 \%$ of all neonatal deaths occur in developing countries (WHO report 2006). In India, the incidence of blood culture proven sepsis was reported as 8.5 per 1,000 live births for the year 20022003 by the National Neonatal Perinatal Database (NNPD report 2002-03). Most of the neonatal sepsis related deaths are preventable if suspected early and treated with appropriate antibiotics. Early-onset neonatal sepsis (EONS) occurs within first $72 \mathrm{~h}$ of life, while the late-onset neonatal sepsis (LONS) occurs between $72 \mathrm{~h}$ to 90 days of life (Sundaram et al., 2009). The varying microbiological pattern of septicemia in children warrants the need for an ongoing review of the causative organisms and their antimicrobial susceptibility pattern.

The bacterial agents implicated in earlyonset sepsis include group B Streptococcus (GBS), Escherichia coli, coagulase-negative Staphylococcus, Haemophilus influenzae and Listeria monocytogenes (AndersonBelly et al., 2010; Maayan-Metzger et al., 2009). The organisms commonly associated with late-onset sepsis include coagulasenegative Staphylococci (CONS), Staphylococcus aureus, Klebsiella pneumoniae, Escherichia coli, Enterobacter spp., Pseudomonas aeruginosa and Acinetobacter species (Kaistha et al., 2009). The bacteriological profile for causative organisms of neonatal sepsis differs significantly between developed and developing countries (Sanghvi and Tudehope, 1996; Stoll et al., 2002) a pneumoniae is the most common bacterial agent causing neonatal sepsis in developing countries, while group B Streptococcus and coagulase-negative staphylococci (CONS) are the common agents in developed countries (Iregbu et al., 2006). Even among developing countries, regional variation in prevalence of the bacterial agents causing neonatal sepsis exists (Kuruvilla et al., 1998; Chacko and Sohi, 2005). Therefore, it is essential to establish the bacteriological profile of organism associated with septicemia. Prompt diagnosis and effective treatment is necessary to prevent deaths and complications due to septicemia.

Physical signs and symptoms are useful in identifying infants and children with septicemia. These clinical characteristics can be good predictors for positive blood culture but they have limited specificity and sensitivity (Tumbarello et al., 2007; Weber et al., The uncertainty surrounding the clinical approach to treatment of neonatal septicemia can be minimized by periodic epidemiological surveys of etiological agents and their antibiotic susceptibility patterns leading to recognition of the most frequently encountered pathogens in a particular neonatal setting.

The rational and correct use of antibiotics requires understanding of common pathogens and their drug sensitivity pattern in the regions. Due to constantly evolving antimicrobial resistant patterns there is the need for constant antimicrobial sensitivity surveillance. This will help clinicians provide safe and effective empirical therapies, develop rational prescription programs and make policy decisions and finally assess the effectiveness of all (Karki et al., 2010). As antibiotic sensitivity pattern to common pathogen has been changing day by day, so it has been necessary to study about bacteriological analysis and antibiotic sensitivity pattern. Determination of antibiotic sensitivity patterns in periodic intervals is mandatory in each region for choosing appropriate antibiotic therapy.

The present study was undertaken to study the bacteriological profile of neonatal septicemia cases and their antibiotic 
susceptibility pattern for planning strategy for the management of these cases.

\section{Materials and Methods}

This prospective observational study was conducted in the department of Microbiology, Govt. Kilpauk Medical College, Chennai, over a period of Two months (July 2015 and August 2015). This study was approved by the Research and Ethical committees of our institute and informed consent was obtained from each patient's next of kin. The samples were collected with proper aseptic precautions. All neonates in whom sepsis was suspected and had at least two positive screening tests were included in the study.

\section{Data Collecting Procedure}

Many infections in the neonatal age group can only be established on the basis of etiological agent removed from blood but a negative blood culture does not rule out the possibility of Neonatal Sepsis. Gold standard for diagnosis of Neonatal Sepsis is isolation of bacterial agent from blood culture. With all aseptic precautions about 1$2 \mathrm{ml}$ of blood is drawn from each neonate. About $1 \mathrm{ml}$ of blood is inoculated into $10 \mathrm{ml}$ of brain heart infusion (BHI) broth and processed as per the protocol and incubated for one week at $37^{\circ} \mathrm{C}$ and is checked daily for evidence of bacterial growth. For positive broth cultures, subcultures are done next day on blood agar, MacConkey's agar and chocolate agar and are incubated at $37^{\circ} \mathrm{C}$ for 24 hours. If no growth occurred on plates after 24 hours, subsequent cultures are done on 2nd, 5th and 7 th day. The grown bacteria are identified by colony morphology, Gram stain and standard biochemical tests. The antibiotic susceptibility testing is performed by KirbyBauer disc diffusion method for the bacterial isolates, as per Clinical and Laboratory Standards Institute guideline (CLSI). ATCC control strains are used accordingly as per standard procedures. Observation made in the Microbiology Department will be documented and compiled using computer software.

\section{Plan of Analysis}

The following variables will be analyzed:

1. Age

2. Sex

3. Microbial species

4. Drug resistance as in antibiogram forms

The pathogens are accessed for resistance against the most commonly used eight anti microbials.

The antimicrobials under the study were:

$\begin{array}{ll}\text { Fluroquinolones } & \text { : Ciprofloxacin } \\ \text { Penicillin } & \text { : Ampicillin } \\ \text { Aminoglycosides } & \text { : Gentamicin } \\ \text { Glycopeptides antibiotics } & \text { : Vancomycin } \\ \text { Macrolide antibiotics } & \text { : Erythromycin } \\ \text { Tetracyclines } & \text { : Doxycycline } \\ \text { Cephalosporins } & \text { : Ceftazidime, }\end{array}$

Cefmetazole, Cephalexin

\section{Results and Discussion}

83 suspected clinical cases of sepsis was included in the study and analysed for antibiotic sensitivity. Among culture positive there was 51 male $(61.5 \%)$ neonates and 32 female $(38.5 \%)$ The male: female ratio stands at 1.6:1.Fig:1.

Early On Set Neonatal Sepsis cases were found higher than Late on Set Neonatal Sepsis. EONS were seen in 71 cases $(85.5 \%)$ and 12 cases recorded LONS (14.5\%).fig:2. 
Detailed etiology of 83 isolates proves that Gram negative bacilli 47/83 (56.6\%) dominate the picture when compared to Gram positive cocci 36/83 (43.4\%). Fig: 3

\section{Antibiotic Sensitivity of Klebsiella}

$90 \%$ of the Klebsiella show sensitivity to Amikacin. None of them are found to be sensitive towards Ampicillin and Cephalexin. Sensitivity to Gentamicin is as low as $27 \%$ (given in Table: 1 )

\section{Antibiotic Sensitivity of CONS}

CONS showed $100 \%$ sensitivity to Vancomycin, Doxycycline and Amikacin. Low sensitivity pattern is recorded in case of Ampicillin (0\%) and Ciprofloxacin $(8.6 \%)$ given in Table 2.

\section{Antibiotic Sensitivity of Staphylococcus aureus}

Staphylococcus aureus was found to show $100 \%$ sensitivity to Vancomycin, Erythromycin, Doxycycline and Amikacin. It showed 0\% sensitivity to Ciprofloxacin. given in Table:3.

\section{Antibiotic Sensitivity of Acinetobacter}

Third and Second generation Cephalosporins were found to be $100 \%$ effective against Acinetobacter. First generation cephalosporin, Cephalexin as well as Ciprofloxacin could not resist the growth of Acinetobacter given in Table: 4 .

\section{Antibiotic Sensitivity of Enterobacter}

Second and third generation Cephalosporins yet again showed $100 \%$ efficiency in restricting the growth of Enterobacter. Ampicillin, Gentamicin, Ciprofloxacin and Cephalexin failed to restrict the growth of Enterobacter (0\% sensitivity) given in Table:5.

\section{Antibiotic Sensitivity of Pseudomonas}

Pseudomonas showed high sensitivity $(100 \%)$ to second and third generation cephalosporins, Amikacin and Ciprofloxacin. Pseudomonas showed 0\% sensitivity to Ampicillin, Gentamicin. Given in Table: 6 .

Septicemia is still a major cause of mortality and morbidity in the first month of life. New treatment approaches are being explored throughout the world because of its rapidly changing pathogen spectrum and high mortality rate. Area based knowledge of the bacteriological spectrum is essential because the first antibiotic administered will not wait for the culture results. Keeping in mind the high mortality associated with neonatal septicemia, a right choice for such empiric theory is of utmost importance. Periodic revision of this knowledge is equally important since the spectrum of causative pathogens varies in same place from time to time over a period of time.

In our study, 83 out of 232 cases were culture positive, giving a culture positivity rate of around $35.77 \%$. This is in accordance with the study conducted by Uddin Ahmed et al., (35\%), Edwin Dias et al., (35\%). This is in contrast to study conducted by Roy et al., (47.50\%), R.S.Jaswal et al., (42\%) and Tallur et al., (64.87\%). In the present study, males were more affected than their female counterparts, males contributing $61 \%$ of culture positive cases and the Male: Female ratio being 1.6:1. This is comparable to the study conducted by Tallur et al., Uddin Ahmed et al., and P.Jyothi et al., Khatua et $a l$., postulated that the factors regulating the production of gamma globulins are most likely situated on the $\mathrm{X}$ chromosome. 
Presence of single $\mathrm{X}$ chromosome in male infants thus confers less immunological protection compared to their female counterparts.

In our study, $85.5 \%$ of cases are reported in the early days of life, Early Onset Neonatal Sepsis which goes hand in hand with other studies conducted by Tallur et al., (83.47\%), Roy et al., (71.30\%).

The proportion of Early Onset Neonatal Sepsis cases may be due to immature immunological responses of neonates in the first week of life, making them more susceptible to infections in this period. Gram negative bacilli were found to be the commonest cause of neonatal septicemia $(56.5 \%)$. The foetus is frequently exposed to enteric bacteria during the course of maternal peripartal infections. In those instances in which the same agent was recovered from mother and infant, gram negative bacteria were predominant. Post natally the infant may get exposed to Gram negative organisms through humidification apparatus, resuscitation equipment or articles used in daily care. Since the neonates lack normal flora at birth he/she may become heavily colonized with Gramnegative bacteria in sites where these agents are not normally found. The newborn infant has been shown to have a lack of serum bactericidins against Gram-negative bacilli.

Table.1 Antibiotic sensitivity of Klebsiella

\begin{tabular}{|c|c|c|}
\hline Antibiotic & $\begin{array}{c}\text { No. of samples } \\
\text { showing sensitivity }\end{array}$ & \% of sensitivity \\
\hline Ceftazidime & 14 & $42.42 \%$ \\
\hline Cefmetazole & 33 & $100 \%$ \\
\hline Cephalexin & 0 & $0 \%$ \\
\hline Ciprofloxacin & 25 & $27.2 \%$ \\
\hline Gentamicin & 9 & $90.9 \%$ \\
\hline Amikacin & 30 & $0 \%$ \\
\hline Ampicillin & 0 & $75 \%$ \\
\hline
\end{tabular}


Table.2 Antibiotic sensitivity of CONS

\begin{tabular}{|c|c|c|}
\hline Antibiotic & $\begin{array}{c}\text { No. of samples } \\
\text { showing sensitivity }\end{array}$ & $\begin{array}{c}\text { \% of samples } \\
\text { showing } \\
\text { sensitivity }\end{array}$ \\
\hline Vancomycin & 23 & $100 \%$ \\
\hline Doxycycline & 23 & $100 \%$ \\
\hline Erythromycin & 7 & $30.4 \%$ \\
\hline Ciprofloxacin & 2 & $8.6 \%$ \\
\hline Gentamicin & 9 & $39.1 \%$ \\
\hline Amikacin & 23 & $100 \%$ \\
\hline Ampicillin & 0 & $0 \%$ \\
\hline
\end{tabular}

Table.3 Antibiotic Sensitivity of Staphylococcus aureus

\begin{tabular}{|c|c|c|}
\hline Antibiotic & $\begin{array}{c}\text { No. of samples } \\
\text { showing sensitivity }\end{array}$ & $\begin{array}{c}\text { \% of } \\
\text { sensitivity }\end{array}$ \\
\hline Vancomycin & 13 & $100 \%$ \\
\hline Doxycycline & 13 & $100 \%$ \\
\hline Erythromycin & 13 & $100 \%$ \\
\hline Ciprofloxacin & 0 & $0 \%$ \\
\hline Gentamicin & 3 & $23.07 \%$ \\
\hline Amikacin & 13 & $100 \%$ \\
\hline Ampicillin & 4 & $30.7 \%$ \\
\hline
\end{tabular}


Table.4 Antibiotic Sensitivity of Acinetobacter

\begin{tabular}{|l|c|c|}
\hline Antibiotic & $\begin{array}{c}\text { No. of samples } \\
\text { showing sensitivity }\end{array}$ & $\begin{array}{c}\text { \% of } \\
\text { sensitivity }\end{array}$ \\
\hline Ceftazidime & 7 & $100 \%$ \\
\hline Cefmetazole & 7 & $100 \%$ \\
\hline Cephalexin & 0 & $0 \%$ \\
\hline Ciprofloxacin & 0 & $0 \%$ \\
\hline Gentamicin & 3 & $23.07 \%$ \\
\hline Amikacin & 7 & $100 \%$ \\
\hline Ampicillin & 2 & $28.5 \%$ \\
\hline
\end{tabular}

Table.5 Antibiotic Sensitivity of Enterobacter

\begin{tabular}{|l|c|c|}
\hline Antibiotic & $\begin{array}{c}\text { No. of samples } \\
\text { showing }\end{array}$ & $\begin{array}{c}\text { \% of } \\
\text { sensitivity }\end{array}$ \\
\hline Ceftazidime & 5 & $100 \%$ \\
\hline Cefmetazole & 5 & $100 \%$ \\
\hline Cephalexin & 0 & $0 \%$ \\
\hline Ciprofloxacin & 0 & $0 \%$ \\
\hline Gentamicin & 0 & $0 \%$ \\
\hline Amikacin & 1 & $20 \%$ \\
\hline Ampicillin & 0 & $0 \%$ \\
\hline
\end{tabular}

Table.6 Antibiotic Sensitivity of Enterobacter

\begin{tabular}{|c|c|c|}
\hline Antibiotic & $\begin{array}{c}\text { No. of samples } \\
\text { showing sensitivity }\end{array}$ & $\begin{array}{c}\text { \% of } \\
\text { sensitivity }\end{array}$ \\
\hline Ceftazidime & 2 & $100 \%$ \\
\hline Cefmetazole & 2 & $100 \%$ \\
\hline Cephalexin & 1 & $50 \%$ \\
\hline Ciprofloxacin & 2 & $100 \%$ \\
\hline Gentamicin & 0 & $0 \%$ \\
\hline Amikacin & 2 & $100 \%$ \\
\hline Ampicillin & 0 & $0 \%$ \\
\hline
\end{tabular}


Int.J.Curr.Microbiol.App.Sci (2016) 5(6): 511-521

Fig.1 Sex Distribution in Patients

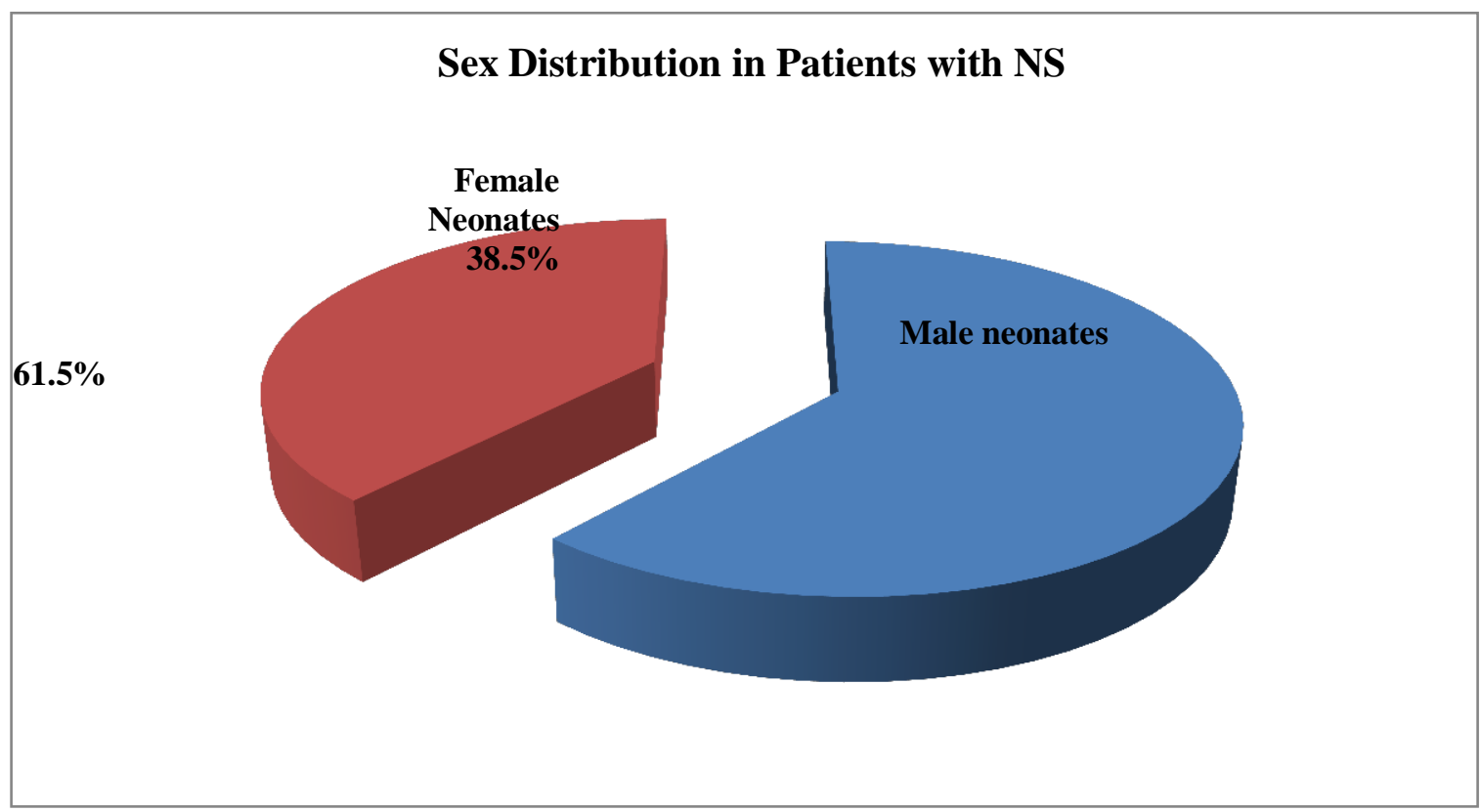

Fig.2 Based on Onset of Neonatal Sepsis

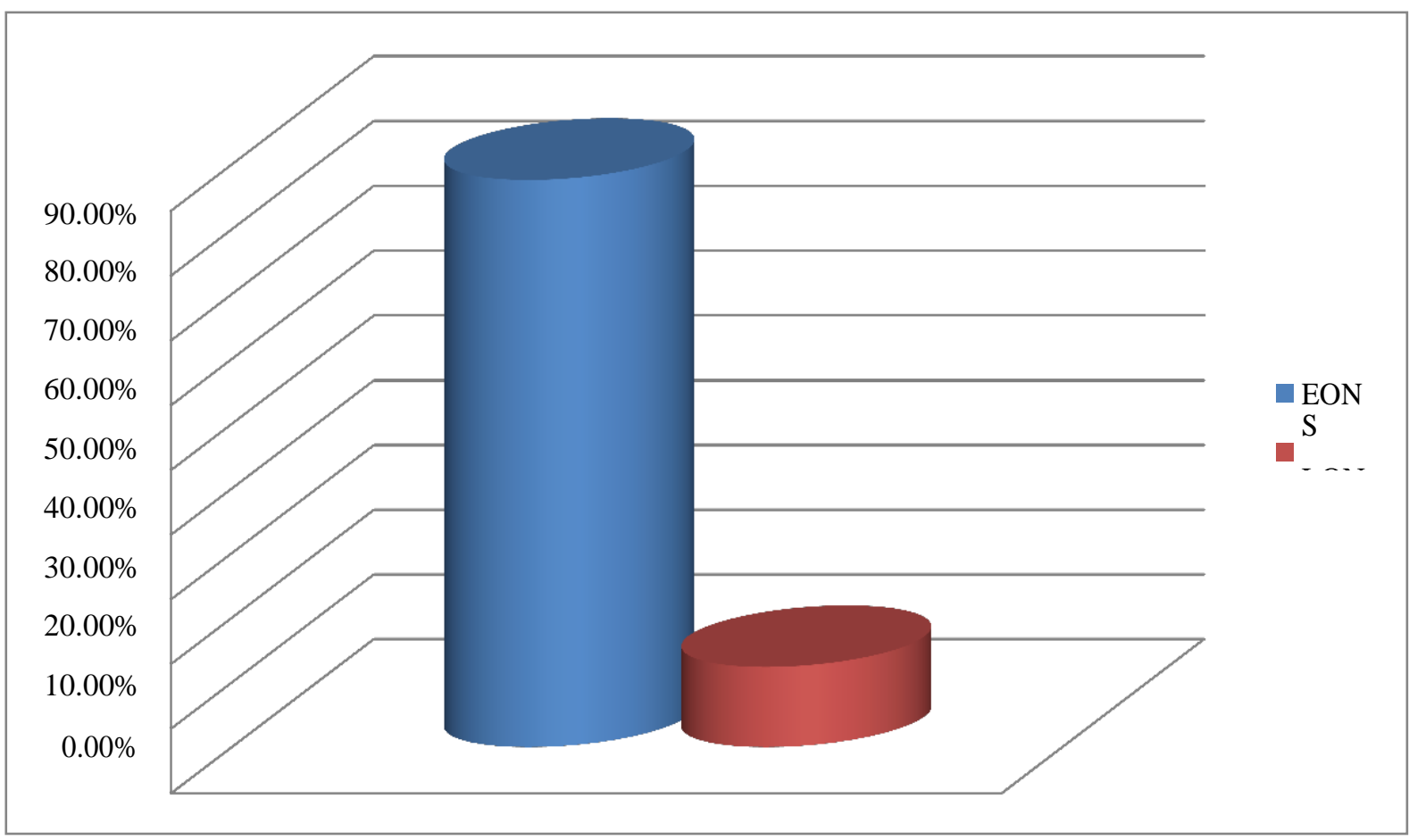


Fig.3 Causative organism in Neonatal Sepsis

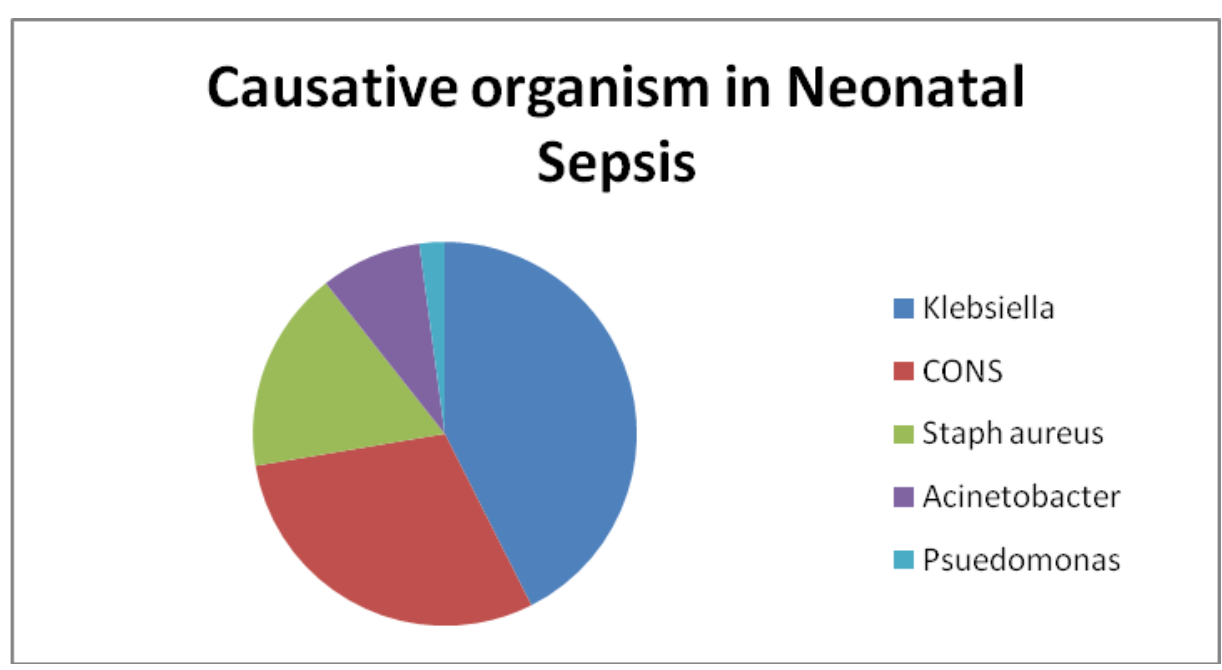

These antibodies against somatic or "O" antigens in Gram negative bacteria are in the gamma-M fraction which is not passed transplacentally from mother to foetus.

Yet another contributing factor might be the recent rampant use of antibiotics both in the mother and the infant, which would tend to select out the relatively more resistant Gram-negative organisms. Hence; Gramnegative organisms are commonest cause of neonatal septicemia. In this study, the most frequent isolate was Klebsiella pneumonia $33 / 83(39.75 \%)$. This was in accordance with other Indian studies NNPD 2003, Roy et al and second most common isolate is CONS23/83(27.7\%). Initially Ampicillin is frequently used as first choice drug for initial treatments of acute infections without bacteriological data. But now many organisms are found to have developed resistance against this group casting doubts about their efficacy. In this study Kelbsiella, CONS, Enterobacter and Pseudomonas (totally $33+23+5+2=63 / 83$ around $75.9 \%$ ) showed $0 \%$ sensitivity. Thus including Ampicillin as part of empirical treatment for Neonatal Sepsis is not justified and can cause treatment failure. Klebsiella showed 90.9\% sensitivity against Amikacin which is in accordance with the study conducted by Bambala et al., in 2011. All the Gram negative bacilli were found to be highly sensitive to third generation cephalosporins especially Cefperazone sulbactum All the gram positive isolates showed $100 \%$ sensitivity to Vancomycin. Tallur et al., showed that all the Gram positive isolates were $100 \%$ suscepitible to Vancomycin. Ciprofloxacin showed less efficiency in case of Gram positive isolates which is in contrast to the study conducted by Dias et al in 2010 . Cephalosporins still remain the most effective drugs for the treatment of Neonatal Sepsis

In conclusion, from our study, it was concluded that Gram negative bacilli take a major share in the spectrum of pathogens causing Neonatal Sepsis. Klebsiella was the most common isolate and it is highly sensitive to third generation Cephalosporins and Amikacin. In case of Gram positive isolates, Vancomycin is found to be highly effective. An antibiotic policy should be formulated in the hospital and depending on the antibiotic sensitivity pattern of the 
isolated pathogens, antibiotics should be used. It will be important to continue the tracking of neonatal septicemia in order to closely monitor the changes in trends, to obtain information for empiric antibiotic therapy and to act rapidly in case of emergencies. Since Govt. Kilpauk Medical College being a tertiary health care centre, most of its sepsis cases are referred ones. Hence awareness should be created about institutional deliveries along with antenatal and postnatal care.

\section{References}

Anderson-Berry, A.L., Bellig, L.L., Ohning, B.L. 2010. Neonatal sepsis.[Internet]. emedicine Pediatrics: Cardiac Disease and Critical Care Medicine 2010; 978352 [Updated 2010 Feb 23; Cited 2010 Sep 22]. Available from: http://emedicine.medscape.com/ article/978352-overview.

Bizzaro, M.J., Raskind, C., Baltimore, R.S., Gallagher, P.G. 2005. Seventy-five years of neonatal sepsis at yale : 1928-2003. Pediatrics, 116: 595-602.

Bambala, P.Z. et al. 2011. Neonatal Sepsis in a Tertiary Care Hospital In South India: Bacteriological Profile And Antibiotic Sensitivity Pattern. Indain J. Pediatr., 78(4): 413-417.

Chacko, B., Sohi, I. 2005. Early onset neonatal sepsis. Indian J. Pediatr., 72: 23-26.

Dias, E., Brain, P. The Bacterial profile of Neonatal Septicemia In a Rural Hospital In South India. J. Clin. Diag. Res., 4: 3327-3330.

Gotaff, S.P., Behrman, R.E. 1970. Neonatal septicemia. J. pediatr., 76(1): 142-153.

Iregbu, K.C., Elegba, O.Y., Babaniyi, I.B. 2006. Bacteriological profile of neonatal septicaemia in a tertiary hospital in Nigeria. Afr. Health Sci., 6: 151-154.

Jaswal, R.S., Kaushl, R.K., Asha Goel, Kushla Pathania. 2003. Role of C-reactive protein in Deciding Duration of Antibiotic Therapy in Neonatal septicemia. Indian
Pediatrics, 40: 880-883.

Karki, R., Bhatta, D.R., Malla, S., Dumre, S.P. 2010. Cholera incidence among patients with diarrhea visiting National Public Health Laboratory, Nepal. Jpn. J. Infect. Dis., 63: 185-187.

Kaistha, N., Mehta, M., Singla, N., Garg, R., Chander, J. 2009. Neonatal septicemia isolates and resistance patterns in a tertiary care hospital of North India. $J$. Infect. Dev. Ctries, 4: 55-57.

Khatua et al. 1986. "Neonatal septicemia". Indian J. Pediatr., 53(4): 509-514.

Kuruvilla, K.A., Pillai, S., Jesudason, M., Jana, A.K. 1998. Bacterial profile of sepsis in a neonatal unit in south India. Indian Pediatr., 35: 851-858.

Donowitz, L.G. "Nosocamial infection in neonatal intensive care units," American J. Infect. Control, vol, 17, no. 5, pp. 250257.

Brady, M.T. 2005. "Health care-associated infections in the neonatal intensive care unit," American Journal of Infection Control, vol. 33, no. 5, pp.268-275.

Maayan-Metzger, A., Barzilai, A., Keller, N., Kuint, J. 2009. Are the "good old" antibiotics still appropriate for earlyonset neonatal sepsis? A 10 year survey. Isr. Med. Assoc. J., 11: 138-142.

Mahapatra, A., Ghosh, S.K., Mishra, s., Pattnaik, D., Pattnaik, K., Mohanty, S.K. 2002. Enterobacter cloacae: A predominant pathogen in neonatal septicemia. Indian J. Med. Microbiol., 20(2): 110-112, 2002.

Bjorkqvist, M., M. Liljedahl, J. Zimmermann, J. Schollin, b. Soderquist. 2010. "Colonization pattern of coagulasenegative staphylococci in preterm neonates and the relation to bacteremia," European J. Clin. Microbiol. Infect. Dis., vol. 29, no. 9, pp. 1085-1093.

National Neonatal Perinatal Database. [Internet]. NNPD report 2002-03 [cited 2010 Sep 22]. Available from: http:// www.newbornwhoccorg/pdf/nnpd_repor t_2002-03 PDF.

Nawshad Uddin Ahmed, A.S.M., Azad 
Chowdhury, M.A.K., Mahbul Hoque, Gary, L., Carmstdt. 2002. Clinical and bacteriological Profile of Neonatal Septicemia in a Tertiary level Pediatric Hospital in Bangladesh. Indian Pediatrics., 39: 1034-1038.

Overall James, C. Jr. 1970. Neonatal bacterial meningitis; Analysis of predisposing factors and outcome compared with matched control subjects. J. Pediatr., 76(4): 499-511.

Jyothi, P., Metri, C.B., Peerapur, V.B. 2013. Bacteriological profile of neonatal septicemia and antibiotic susceptibility pattern of the isolates. J. Nat. Sci. Bio. Med., 4(2):306-309.

Graham, P.L., M.D. Begg, E. Larson, P. DellaLatta, A. Allen, L. Saiman. 2006. "Risk factors for late onset gram-negative sepsis in low birth weight infants hospitalized in the neonatal intensive care unit," The Pediatric Infect. Dis. J., vol 25, no. 2, pp. 113-117.

Sanghvi, K.P., Tudehope, D.I. 1996. Neonatal bacterial sepsis in a neonatal intensive care unit: a 5 year analysis. J. Paediatr. Child Health, 32: 333-338.

Shashikala, S., Tallur, Kasturi, A.V., Shobha, D., Nadgir, Krishna, B.V.S. 2000. Clinico bacteriological Study of Neonatal Septicemia in Hubli. Indian J. Pediatr., 67(3): 169-174.

Qazi, S.A., Stoll, B.J. 2009. Neonatal Sepsis : A major global public health challenge The Pediatric Infect. Dis. J., vol. 28, supplement 1, pp.S1-S2.

Coasta, S.F., M.H. Miceli, E.J. Anaissie. 2004. "Mucosa or skin as source of Coagulase negative staphylococcal bacteremia?"
Lancet Infect. Dis., vol. 4, no. 5, pp. 278286.

Stoll, B.J., Hansen, N., Fanaroff, A.A., et al. 2002. Changes in pathogens causing early-onset sepsis in very-low-birthweight infants. N. Engl. J. Med., 347: 240-247.

Sundaram, V., Kumar, P., Dutta, S., et al. 2009. Blood culture confirmed bacterial sepsis in neonates in a North Indian tertiary care center: changes over the last decade. Jpn. J. Infect. Dis., 62: 46-50.

Roy, I., Jain, A., Kumar, M., Agarwal, S.K. 2002. Bacteriology of Neonatal Septicemia in Tertiary care Hospital of Northern India. Indian J. Med. Microbiol., 4(2): 306-309.

Tumbarello, M., Sanguinetti, M., Montuori, E., Trecarichi, M.E., Posteraro, B., Fiori, B., Citton, R., D'Inzeo, T., Fadda, G., Cauda, R., Spanu, T. 2007. Predictors of mortality in patients with bloodstream infections caused by extended-spectrumlactamase-producing enterobacteriaceae: Importance of inadequate initial antimicrobial treatment. Antimicrob. Agents Chemother., 51: 1987-1994.

Weber, M.W., Carlin, J.B., Gatchalian, S., Lehmann, D., Muhe, L., Mulholland, E.K. 2003. WHO Young infants study group: predictors of neonatal sepsis in developing countries. Pediatr. Infect. Dis. J., 22(8): 711.

World Health Organization (WHO). 2006. Neonatal and perinatal mortality: country, regional and global estimates. WHO, Geneva.

\section{How to cite this article:}

Leela, K.V., R. Narayana Babu, Sugunya, Venkata Madhu Prasad and Ramisetty Raaga Deepa. 2016. Study of Bacterial Profile in Neonatal Sepsis and their Antibiotic Sensitivity Pattern in a Tertiary Care Hospital. Int.J.Curr.Microbiol.App.Sci. 5(6): 511-521. doi: http://dx.doi.org/10.20546/ijcmas.2016.506.057 